\title{
Studies on Humic Acids
}

\section{VII. * The Structure of the Dihydroxy-dioxidoterphenyl Obtained by the Action of Sulphuric Acid on p-Benzoquinone}

\author{
HOLGER ERDTMAN and NILS E. STJERNSTROM
}

Organisk-kemiska Institutionen, Kungl. Tekniska Högskolan, Stockholm, Sweden

\begin{abstract}
Acid polymerisation of $p$-benzoquinone gives, among other products, a dioxidoterphenyl for which structure $\mathrm{V}$ has been suggested. This has now been shown to be incorrect; the structure is very probably $\mathrm{X}$. Arguments in favour of this view are presented.
\end{abstract}

$Q_{\mathrm{a}}$ uinones sometimes exhibit a considerable reactivity in the presence of acids undergoing intermolecular coupling reactions with the formation of di- or terphenyl derivatives and amorphous high molecular weight quinonoid products of unknown constitution which are of obvious interest in connection with the chemistry of humic acids and melanins.

Thus, even with very dilute sulphuric acid, the highly reactive methoxyquinone $I$ is rapidly and almost' quantitatively transformed into the insoluble diphenyl derivative II (or the intermolecular quinhydrone alternative) which is relatively stable to acids. ${ }^{1}$ The far less reactive toluquinone undergoes a similar change in the presence of strong sulphuric acid with the formation of toluhydroquinone, a diphenyl derivative analogous to $\mathrm{II}\left(\mathrm{CH}_{3}\right.$ instead of $\left.\mathrm{OCH}_{3}\right)$, and about $10 \%$ of a terphenyl derivative to which the structure III has been assigned. The main reaction product is an amorphous, quinonoid "polymer".

In the same way $p$-benzoquinone yields about $50 \%$ hydroquinone, a large amount of polymeric material and a small amount of a terphenyl derivative for which structure $V$ has been suggested ${ }^{2}$.

It appears probable that these quinones react in a similar way with acids and alkali since hydroquinones and quinonoid polymers are formed in both cases. Intermediate low molecular weight polyphenols have been less frequently isolated from the products of alkaline decomposition of quinones but the formation of a very small amount of dihydroquinone has been demonstrated in the case of $p$-benzoquinone ${ }^{3}$.

* Part VI. Acta Chem. Scand. 8 (1954) 1442.

Acta Chem. Scand. 13 (1959) No. 4 
<smiles>COC1=CC(=O)C(OC)=CC1=O</smiles>

I

II

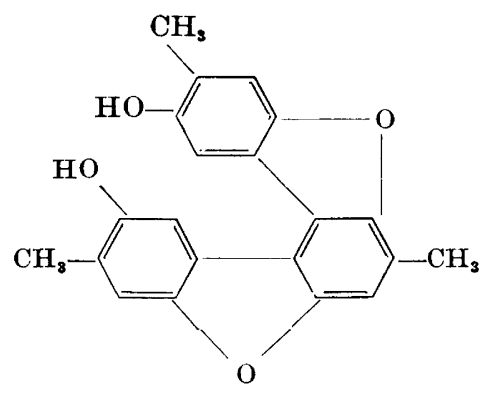

III (III a: $\mathrm{C}_{2} \mathrm{H}_{5}$ instead of $\mathrm{CH}_{3}$ )

(The positions of the alkyl groups in III and III a uncertain)<smiles></smiles>

The termolecular products obtained with acids are probably intermediates in the acid polymerisation of benzoquinone and toluquinone which have been stabilised by dehydration and removed from further reactions. Methoxyquinone is exceptional in its preferential formation of a dimer.

Some years ago Schimmelschmidt ${ }^{4}$ described the dioxidoterphenyl VIII obtained by alkali fusion of $2,2^{\prime \prime}$-dichloro- $z^{\prime}, 5^{\prime}$-dihydroxy-p-terphenyl. It melts at $265-266^{\circ}$. We have synthesised the same compound in a different way starting with 2 -bromocyclohexanone ${ }^{5}$ and the disodium selt of hydroquinone. These compounds reacted to give 1,4-di-(2-ketocyclohexyloxy)-benzene (VI) which was treated with a polyphosphoric acid mixture to give what must be $3,4,5,6,3^{\prime \prime}, 4^{\prime \prime}, 5^{\prime \prime}, 6^{\prime \prime}$-octahydro-2, $2^{\prime}, 5^{\prime}, 2^{\prime \prime}$-dioxido- $p$-terphenyl (VII) as a result of intramolecular condensation. This substance was dehydrogenated with palladium to give a compound identical with Schimmelschmidt's compound VIII. The same compound has also been obtained in the following way. 4-Iodo-resorcinol dimethyl ether and 2,5-diiodo-hydroquinone dimethyl ether were condensed by the Ullmann procedure. The resulting hexamethoxyterphenyl (IX) when heated with hydrobromic acid furnished a dihydroxy- 


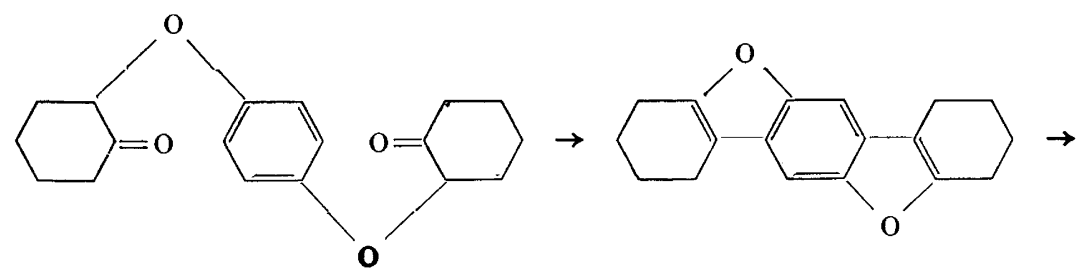

VI

VII

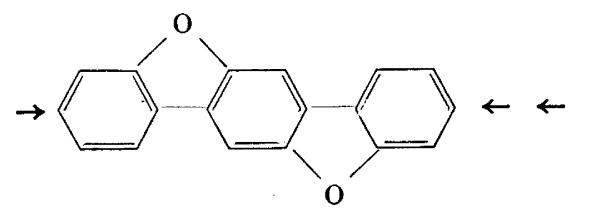

VIII

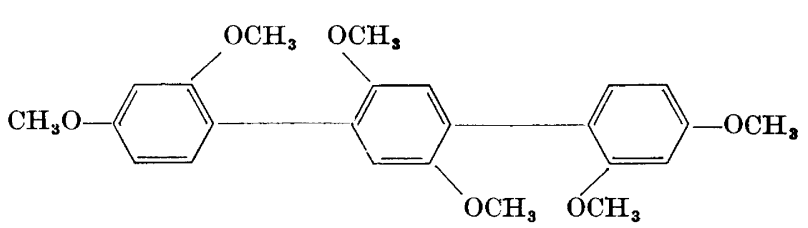

IX

dioxido- $p$-terphenyl which on distillation with zinc dust gave compound VIII (Stjernström, forthcoming publication). Schimmelschmidt's substance must have the structure he assigned to it.

In order to relate the dihydroxy-dioxidoterphenyl from $p$-benzoquinone with Schimmelschmidt's compound it was subjected to distillation with zinc dust.. The neutral product obtained was, however, isomeric, not identical with VIII. Moreover, a compound which must have the structure V was obtained by prolonged boiling of the hexamethoxyterphenyl IV ${ }^{6}$ with hydrobromic acid. It was isomeric with the dihydroxy-dioxidoterphenyl obtained from $p$-benzoquinone and the suggested structure (V) for the compound from $p$-benzoquinone must therefore be incorrect.

Structure $V$ was advanced on the likely assumption that $p$-benzoquinone would polymerise stepwise and, for sterical reasons, preferentially in the 2,5positions. In the case of toluquinone this is not possible because of the obstructing methyl groups and condensation with other molecules of toluquinone can only take place (the slight possibility of methyl group migration being ignored) in positions 5 and 6 in order to provide a tri-toluhydroquinone able to furnish a dioxidoterphenyl by dehydration.

The exact mechanism of the quinone polymerisation is not known and it is, of course, possible that the hypothesis that trihydroquinones are formed first is an oversimplification. At present, the only likely alternative to structure $\mathrm{V}$ for the termolecular compound from $p$-benzoquinone appears to be $\mathrm{X}$ and attempts were therefore made to convert compound III into $\mathrm{X}$ by elimination of the methyl groups.

The dimethyl ether of III was oxidised in the hope that a tricarboxylic acid might be formed which on decarboxylation should give the dimethyl ether of $X$. All attempts to effect this oxidation with permanganate or chromic acid invariably resulted in acid mixtures, from which no pure tricarboxylic acid could be obtained.

Acta Chem. Scand. 13 (1959) No. 4 


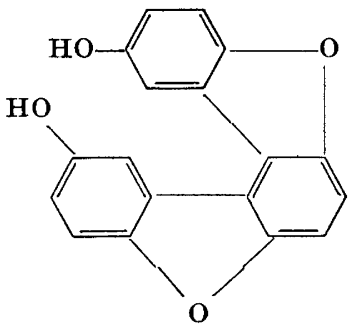

$\mathrm{X}$

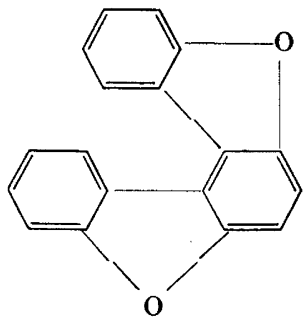

$\mathrm{XI}$

On decarboxylation neutral products were obtained which were very similar to the dimethyl ether of the dihydroxy-dioxidoterphenyl from $p$ benzoquinone but they were obviously not pure compounds. As the oxidation of the methyl ether of the toluquinone product appeared to offer insurmountable difficulties ethylquinone was subjected to treatment with sulphuric acid and a termolecular product, obviously the ethyl analogue of III (III a) was obtained. The dimethyl ether of III a was oxidised with potassium permanganate in pyridine and an acid product was obtained which on decarboxylation furnished a neutral compound identical with the dimethyl ether of the termolecular product from $p$-benzoquinone.

It follows that the dihydroxy-dioxidoterphenyl from $p$-benzoquinone will almost certainly have the structure $X$.

\section{EXPERIMENTAL}

\section{All melting points are uncorrected}

1,4-Di-(2-ketocyclohexyloxy)-benzene (VI). 2-Bromo-cyclohexanone was prepared according to Trippett ${ }^{5}$. Sodium $(2.3 \mathrm{~g})$ was dissolved in absolute ethanol $(50 \mathrm{ml})$ and a solution of hydroquinone $(5.5 \mathrm{~g})$ in absolute ethanol $(50 \mathrm{ml})$ was added. The alcohol was evaporated under reduced pressure care being taken to avoid oxidation. The dry hydroquinone sodium salt, 2-bromocyclohexanone (17.6 g) and dry benzene $(200 \mathrm{ml})$ were stirred for three days in a coal gas atmosphere. After filtration and evaporation of the solvent a dark brown oil was obtained that soon crystallised partly on cooling. The crystals were collected and recrystallised from $n$-butanol. Yield 1 g. M. p. 190.5-193. (Found: C 71.4; $\mathrm{H}$ 7.2. Calc. for $\mathrm{C}_{18} \mathrm{H}_{28} \mathrm{O}_{4}$ : C 71.5; $\mathrm{H}$ 7.3.)

$3,4,5,6,3^{\prime \prime}, 4^{\prime \prime}, 5^{\prime \prime}, 6^{\prime \prime}$-Octahydro-2,2, $5^{\prime}, 2^{\prime \prime}$-dioxido-p-terphenyl (VII). 1,4-Di-(2-ketocyclohexyloxy)-benzene (VI) (720 mg) was added to a solution of phosphorus pentoxide $(10 \mathrm{~g})$, in phosphoric acid $(d 1.75,20 \mathrm{ml})$. The mixture was stirred at $100^{\circ}$ for $3 \mathrm{~h}$ and then diluted with water. The precipitate was collected, washed and dried. The gray, crude product $\left(520 \mathrm{mg}\right.$ ) was recrystallised from $n$-butanol, m. p. 201-202 $2^{\circ}$ (Found: C 80.5; $\mathrm{H}$ 6.7. Calc. for $\mathrm{C}_{18} \mathrm{H}_{18} \mathrm{O}_{2}$ : $\mathrm{C}$ 81.2; $\mathrm{H}$ 6.8.)

$2,2^{\prime}, 5^{\prime}, 2^{\prime \prime}$-Dioxido-p-terphenyl (VIII). Compound VII (150 mg) was mixed with a palladium-charcoal catalyst $(10 \% \mathrm{Pd}, 100 \mathrm{mg})$ and the mixture was heated to $230^{\circ}$ for $5 \mathrm{~h}$ in an atmosphere of nitrogen. The reaction product was extracted with boiling bromobenzene from which the substance crystallised on cooling. Yield $60 \mathrm{mg}, \mathrm{m}$. p. 265.5- 
266.5 . Mixed melting point with Schimmelschmidt's dioxidoterphenyl, generously placed at our disposal by Farbwerke Höchst, showed no depression (m. p. 265-266 ${ }^{\circ}$.

$2,6^{\prime}, 3^{\prime}, 2^{\prime \prime}$-Dioxido-o-terphenyl $(X I) . \quad 5,5^{\prime \prime}$-Dihydroxy-2,6', $3^{\prime}, 2^{\prime \prime}$-dioxido-o-terphenyl (X) was prepared by acid polymerisation of $p$-benzoquinone according to Erdtman ${ }^{2}$. This phenol ( $1 \mathrm{~g})$ was thoroughly mixed with zinc dust $(10 \mathrm{~g})$ and the mixture was introduced into $a$ hard melting glass tube $(1 \times 50 \mathrm{~cm})$ followed by zinc dust $(20 \mathrm{~g})$ and zinc dust impregnated pumice. Carbon dioxide was passed through the tube to remove oxygen. The pumice and the zinc dust layer were then heated until red hot followed by similar heating of the phenol-zinc dust layer. After about twenty minutes some $300 \mathrm{mg}$ of reduced material could be collected from the cool zone of the tube. The substance was recrystallised from acetic acid and sublimed in vacuo, m. p. 143-144.. (Found: C 83.4; $\mathrm{H}$ 4.0. Calc. for $\mathrm{C}_{18} \mathrm{H}_{10} \mathrm{O}_{2}$ : C 83.7; $\mathrm{H}$ 3.9.)

$5,5^{\prime \prime}$-Dihydroxy-2,2, $2^{\prime}, 2^{\prime \prime}$-dioxido-p-terphenyl $(V)$ and its dimethyl ether. 2,5, $2^{\prime}, 5^{\prime}, 2^{\prime \prime}$, $5^{\prime \prime}$-Hexamethoxy $\cdot p$-terphenyl ${ }^{6}$ (IV) $(440 \mathrm{mg})$ was heated under reflux with hydrobromic acid $(48 \%, 25 \mathrm{ml})$ in an atmosphere of carbon dioxide for three days. The reaction mixture was diluted with water $(100 \mathrm{ml})$ and filtered. The collected phenol $(300 \mathrm{mg})$ was dark blue due to superficial oxidation. M. p. $c a 330^{\circ}$ (decomp.). The phenol was suspended in methanol and quantitatively converted to the corresponding dimethyl ether by methyl. ation with an excess of dimethyl sulphate and sodium hydroxide $(40 \%)$. The dimethyl ether was recrystallised from dioxane and sublimed in vacuo, m. p. 255-257 . (Found: C 75.1; $\mathrm{H}$ 4.3. Calc. for $\mathrm{C}_{20} \mathrm{H}_{14} \mathrm{O}_{4}$ : $\mathrm{C}$ 75.5; $\mathrm{H}$ 4.4.) Neither the phenol nor its dimethyl ether were identical with the corresponding compounds from the $p$-benzoquinone polymerisation.

Phenol III $a$ and the corresponding diacetate and dimethyl ether. Ethylquinone was prepared from ethylhydroquinone by the method described by Gulland 7 using ferric chloride as oxidising agent. Ethylquinone $(28 \mathrm{~g})$ was shaken for three days with a mixture of acetic acid $(50 \mathrm{ml})$ and dilute sulphuric acid $(33 \%, 100 \mathrm{ml})$. The thick blue black precipitate was collected, washed thoroughly with water and dried in air. The dry, very finely divided material (19 g) was shaken vigorously with excess zinc dust, acetic anhydride $(45 \mathrm{ml})$ and pyridine $(25 \mathrm{ml})$. The reaction mixture became very hot and after boiling for some minutes it was filtered. Crystals of the diacetate of III a soon began to separate from the filtrate and after one day they were collected, washed with acetic acid and recrystallised from acetic anhydride. Yield $3.5 \mathrm{~g}, \mathrm{~m} . \mathrm{p} .226 .5-227^{\circ}$. (Found: C 73.4; $\mathrm{H}$ 5.9. Calc. for $\mathrm{C}_{28} \mathrm{H}_{28} \mathrm{O}_{6}$ : C 73.4; $\mathrm{H}$ 5.7.)

The acetate was refluxed for one hour in an atmosphere of nitrogen with a mixture of conc. sulphuric acid and acetic acid $(1: 50,100 \mathrm{ml})$. The reaction mixture was poured into a large volume of boiling water. The precipitated phenol was a slightly bluish powder that very rapidly darkened in the air due to superficial oxidation and melted about $230^{\circ}$. Yield almost quantitative.

The freshly prepared phenol suspended in methanol was methylated with an excess of dimethyl sulphate and sodium hydroxide $(40 \%)$. The reaction mixture was poured into water and the product was washed with water, dried and recrystallised from ligroin. (Yield from $2 \mathrm{~g}$ acetate $1.7 \mathrm{~g}$.) The methyl ether melted at $161-162.5^{\circ}$ after sublimation in vacuo. (Found: $\mathrm{C} 78.1 ; \mathrm{H}$ 6.8. Calc. for $\mathrm{C}_{26} \mathrm{H}_{26} \mathrm{O}_{4}$ : C 77.6; $\mathrm{H}$ 6.5.)

Oxidation of the dimethyl ether of phenol III $a$ and decarboxylation of the resulting acid. The dimethyl ether of phenol III a $(540 \mathrm{mg})$ was dissolved in a mixture of pyridine (25 ml) and potassium hydroxide solution $(5 \mathrm{M}, 4 \mathrm{ml})$. The solution was refluxed and very finely divided potassium permanganate $(4 \mathrm{~g})$ was added in small portions during $1.5 \mathrm{~h}$. The reaction mixture was cooled, acidified with dilute hydrochloric acid and decolourised with sulphur dioxide. The yellowish green jelly was collected by centrifuging. The jelly was treated with dilute potassium hydroxide, the neutral material was removed by filtration and the clear filtrate was acidified with hydrochloric acid. The acid amorphous precipitate was collected, washed thoroughly with water and dried in air. It did not crystallise. The dry product $(114 \mathrm{mg})$ was heated for $3 \mathrm{~h}$ at $200^{\circ}$ in an atmosphere of nitrogen together with a copper chromite catalyst $(30 \mathrm{mg})$ and quinoline $(3 \mathrm{ml})$. The filtered reaction mixture was acidified with dilute sulphuric acid and the brown precipitate collected and washed with large amounts of water. After drying and sublimation in vacuo $11 \mathrm{mg}$ of neutral material was obtained, m. p. $173-220^{\circ}$. This material was fractionally sublimed in vacuo, a fraction, m. p. $185-200^{\circ}$, was isolated and recrystallised from a pyridine water mixture and sublimed in vacuo, m. p. $211-214^{\circ}$. The dimethyl 
ether of phenol $X$ from the polymerisation of $p$-benzoquinone melts at $216-218^{\circ}$ and the mixed m. p. was $215-218^{\circ}$. The infrared and ultraviolet spectra of the two samples were identical.

We are grateful to Dr. B. Thomas for checking the manuscript.

\section{REFERENCES}

1. Erdtman, H. Proc. Roy. Soc. London A 143 (1933) 191.

2. Erdtman, H. Proc. Roy. Soc. London A 143 (1933) 228.

3. Erdtman, H. and Granath, M. Acta Chem. Scand. 8 (1954) 811.

4. Schimmelschmidt, K. Ann. 566 (1950) 184.

5. Trippett, S. J. Chem. Soc. 1957421.

6. Erdtman, H., Granath, M. and Schultz, G. Acta Chem. Scand. 8 (1954) 1442.

7. Gulland, J. M. Biochem. J. (London) 26 (1932) 32.

Received January 16, 1959. 